\title{
Impact of socioeconomic status on coronary mortality in people with symptoms, electrocardiographic abnormalities, both or neither: the original Whitehall study 25 year follow up
}

\author{
Harry Hemingway, Martin Shipley, Peter Macfarlane, Michael Marmot
}

International Centre for Health and Society, Department of Epidemiology and Public Health, University College London Medical School, 1-19

Torrington Place, London WC1E 6BT H Hemingway

M Shipley

M Marmot

Department of Research and Development, Kensington and Chelsea and Westminster Health Authority, London H Hemingway

University of Glasgow, Department of

Medical Cardiology, Royal Infirmary, Glasgow

P Macfarlane

Correspondence to: Dr Hemingway (h.hemingway@public-health ucl.ac.uk)

Accepted for publication 1 February 2000

\begin{abstract}
Objectives-To determine the impact of socioeconomic status (SES) on coronary heart disease (CHD) mortality in people with and without prevalent CHD at baseline.

Design-Cohort study with 25 year follow up; prevalent CHD was defined by $Q, S T$ or $T$ wave electrocardiographic (ECG) abnormalities or symptoms (defined by the Rose chest pain questionnaire and self reported doctor diagnosis) or both. SES was defined by four civil service employment grades.

Setting-London.

Participants-17 907 male civil servants aged $40-69$ years.
\end{abstract}

Main outcome measures-CHD mortality ( $n=2695$ deaths).

Results-The lowest versus highest employment grade was associated with increased CHD mortality (age adjusted hazard ratio $1.56(95 \%$ CI $1.2,2.1))$, prevalence of symptoms and, among symptomatic participants only, the prevalence of $\mathbf{Q}, \mathbf{S T}$ or $\mathbf{T}$ abnormalities. Thirty one per cent of CHD deaths occurred in participants with prevalent CHD at baseline. Among participants without $Q$, ST or T abnormality employment grade was associated with CHD mortality; the hazard ratios (lowest $v$ highest grade) adjusted for age, systolic and diastolic blood pressure were 1.72 (95\% CI 1.4, 2.1) for asymptomatic and $1.52(95 \%$ CI $1.1,2.1)$ for symptomatic participants; among participants with $Q$, ST or $T$ abnormality the corresponding hazard ratios were $1.46(95 \%$ CI $0.7,2.9)$ and $1.14(95 \%$ CI $0.6,2.0)$ respectively. Conclusions-SES was inversely associated with CHD mortality in civil servants with and without prevalent CHD at baseline. Further distinguishing the relative contribution of SES to the initiation and progression of $\mathrm{CHD}$ requires repeated measures studies of pre-clinical and clinical measures of CHD.

(F Epidemiol Community Health 2000;54:510-516)

It is widely observed that socioeconomic status (SES) is inversely related to coronary heart disease (CHD) mortality ${ }^{1}$ and furthermore that these differences may be widening. ${ }^{2}$ SES may affect both the risk of developing CHD (aetiology) and survival among CHD cases (prognosis). However, most studies have concentrated on aetiology, with a few studies investigating prognosis ${ }^{34}$ and even fewer the relative impact of SES on aetiology and prognosis. ${ }^{5}$ Examining case fatality in prevalent and incident cases is important; among the larger pool of prevalent cases existing studies have selected patients in randomised trials ${ }^{3}$ or undergoing coronary angiography. ${ }^{4}$ There are few population based studies that have assessed the impact of SES on case fatality in prevalent CHD; this is important in targeting preventive or treatment strategies as well as in identifying mechanisms mediating the effect of SES on CHD risk.

Defining prevalent cases of CHD is, however, problematic. Angina is more prevalent than myocardial infarction, ${ }^{6}$ yet unlike myocardial infarction, it lacks an internationally agreed definition that combines subjective and objective criteria. SES may affect the reporting and perception of symptoms, ${ }^{7}$ access to medical care, diagnosis, treatment and outcome. ${ }^{89}$ By contrast, asymptomatic manifestations of coronary disease are not prone to these effects. In epidemiological studies the electrocardiogram (ECG) is the only widely used tool to investigate asymptomatic changes associated with CHD for which long term mortality follow up data are available. Recent studies suggest that asymptomatic ST-T changes may be valid markers of pre-clinical CHD as they predict CHD mortality, independent of other risk factors. ${ }^{10-12}$ This suggests the potential value of CHD case definitions using specific ECG abnormalities separately in those with and without symptoms.

No previous study has investigated the relation between SES, symptomatic status, ECG abnormalities and CHD events. The objective, therefore, was to compare the impact of SES on CHD mortality in people with and without prevalent $\mathrm{CHD}$ at baseline. The original Whitehall cohort study offers the advantages of a relatively precise measure of SES, civil service employment grade, and a large number of events during 25 years of follow up. ${ }^{13}$

\section{Method}

PARTICIPANTS

Details of the original Whitehall study have been reported elsewhere. ${ }^{14}$ A total of 19019 non-industrial male civil servants aged 40-69 years who were working in London attended the original screening examination between 
Table 1 Employment grade differences in age and age adjusted prevalence of CHD symptoms at baseline and CHD mortality rates over 25 years

\begin{tabular}{lllll}
\hline & \multicolumn{2}{l}{ Employment grade } & & \\
\cline { 2 - 5 } & Administrative & $\begin{array}{l}\text { Professionall } \\
\text { executive }\end{array}$ & Clerical & Other \\
\hline Number of participants (\%) & $958(5.3)$ & $12218(68.2)$ & $2959(16.5)$ & $1772(9.9)$ \\
Age (mean, y) & 50.2 & 50.9 & 54.7 & 57.0 \\
Prevalence ${ }^{\star}$ of CHD symptoms (SE) & $12.1(1.2)$ & $14.5(0.3)$ & $14.8(0.7)$ & $16.9(1.0)$ \\
25 year CHD mortality rate` per 1000 person years (SE) & $6.4(0.9)$ & $7.3(0.2)$ & $9.0(0.4)$ & $10.1(0.6)$ \\
\hline
\end{tabular}

^Age adjusted. $\mathrm{SE}=$ standard error.

September 1967 and January 1970. The response rate was $74 \%$.

\section{SOCIOECONOMIC STATUS}

The civil service grade of employment was used to define SES in four categories (in order of descending SES): administrative, professional or executive, clerical and other grades. These grades reflect salary, education and work responsibility and their monotonic inverse relation with $\mathrm{CHD}$ mortality, independent of conventional risk factors, has been demonstrated. ${ }^{13}{ }^{15}$ For 886 men from the diplomatic service and the British Council employment grading was not comparable. These men have been removed from all analyses.

CASE DEFINITIONS OF PREVALENT CHD

Prevalent CHD was defined by specific ECG abnormalities or symptoms or both. Electrocardiography was undertaken with a Mingograph $31 \mathrm{~B}$, using "multipoint" electrodes. ${ }^{16}$ Five technically adequate complexes were recorded for each of the six limb leads and the middle three complexes were later analysed according to the Minnesota code. ${ }^{17}$ The six limb lead ECG removed the need for participants to undress. Coding was carried out inde- pendently in duplicate by trained and tested technicians. ${ }^{18} \mathrm{Q}$ (Minnesota codes 1:1-1:3), ST (4:1-4:3) and T (5:1-5:3) abnormalities were chosen for defining $\mathrm{CHD}$, since these are the strongest independent predictors of CHD events. Participants were defined as symptomatic if they reported angina, ${ }^{19}$ prolonged chest pain ("pain of possible myocardial infarction") or a previous admission to hospital for CHD. Participants who responded positively to the question "under the general practitioner with heart disease or blood pressure?" were also included in the symptomatic group for two reasons. Firstly, this group had higher age adjusted hazard ratios for CHD mortality than those reporting Rose angina or possible myocardial infarction alone (hazard ratios 3.56, 2.70 and 2.07 respectively). Secondly, adjustment for the use of anti-hypertensive medication, systolic and diastolic blood pressure had little effect on the hazard ratio (decreasing to 3.20), suggesting the greater importance of the "heart disease" than the "blood pressure" component of this group.

CHD RISK FACTORS

The baseline questionnaire obtained details of smoking history. With the participant seated, a single reading of blood pressure was recorded

Table 2 ECG abnormalities: age adjusted prevalence and age adjusted hazard ratios* (95\% confidence intervals) for their effect on all cause and coronary mortality by symptomatic status

\begin{tabular}{|c|c|c|c|c|c|c|}
\hline \multirow[b]{2}{*}{ ECG abnormality (Minnesota code) } & \multicolumn{3}{|c|}{ Asymptomatic $(n=15281) \dagger$} & \multicolumn{3}{|c|}{ Symptomatic $(n=2626) \dagger$} \\
\hline & $\begin{array}{l}\text { \% Prevalence } \\
\text { of ECG } \\
\text { abnormality (n) }\end{array}$ & $\begin{array}{l}\text { All cause } \\
\text { deaths } \\
(n=6381)\end{array}$ & $\begin{array}{l}\text { Coronary } \\
\text { deaths } \\
(n=2023)\end{array}$ & $\begin{array}{l}\text { \% Prevalence } \\
\text { of ECG } \\
\text { abnormality (n) }\end{array}$ & $\begin{array}{l}\text { All cause } \\
\text { deaths } \\
(n=1624)\end{array}$ & $\begin{array}{l}\text { Coronary } \\
\text { deaths } \\
(n=721)\end{array}$ \\
\hline \multicolumn{7}{|l|}{$\mathrm{Q}$ and $\mathrm{QS}$} \\
\hline Large $Q$ and QS (1:1) & $0.04(6)$ & $2.56(1.1,6.2)$ & $1.56(0.2,11.1)$ & $0.7(23)$ & $2.88(1.9,4.4)$ & $3.05(1.7,5.0)$ \\
\hline Intermediate $(1: 2)$ & $0.4(53)$ & $1.48(1.0,2.1)$ & $1.89(1.1,3.3)$ & $1.5(46)$ & $1.44(1.0,2.0)$ & $2.13(1.4,3.2)$ \\
\hline Small $(1: 3)$ & $1.2(187)$ & $1.25(1.0,1.5)$ & $1.38(1.0,2.0)$ & $2.0(59)$ & $1.62(1.2,2.1)$ & $2.43(1.7,3.4)$ \\
\hline Left axis deviation $(2: 1)$ & $2.9(440)$ & $1.13(1.0,1.3)$ & $1.17(0.9,1.5)$ & $4.4(123)$ & $1.16(0.9,1.4)$ & $1.29(0.9,1.8)$ \\
\hline Tall $\mathrm{R}$ wave amplitude $(3: 1)$ & $0.7 \quad(101)$ & $0.98(0.7,1.3)$ & $0.95(0.5,1.6)$ & $0.9(26)$ & $1.77(1.2,2.7)$ & $1.70(0.9,3.3)$ \\
\hline \multicolumn{7}{|c|}{ S-T depression horizontal or downward sloping } \\
\hline$\geqslant 0.5 \mathrm{~mm}$ and $<1 \mathrm{~mm}(4: 2+4: 3)$ & 0.8 (115) & $1.80(1.4,2.2)$ & $2.26(1.6,3.2)$ & $4.0(119)$ & $2.08(1.7,2.5)$ & $2.60(2.0,3.4)$ \\
\hline$\geqslant 1 \mathrm{~mm}(4: 1)$ & $0.1(15)$ & $1.89(0.9,3.8)$ & $2.89(1.1,7.7)$ & $0.6(16)$ & $4.54(2.7,7.6)$ & $5.68(2.9,11.1)$ \\
\hline upwards sloping (4:4) & $0.1 \quad(12)$ & $0.91(0.3,2.4)$ & $0.72(0.1,5.1)$ & $0.3(6)$ & $1.48(0.6,3.6)$ & $1.36(0.3,5.5)$ \\
\hline \multicolumn{7}{|l|}{$\mathrm{T}$ inversion } \\
\hline zero, negative or diphasic $(5: 3)$ & $3.0 \quad(437)$ & $1.42(1.3,1.6)$ & $1.70(1.4,2.1)$ & $5.9(175)$ & $1.77(1.5,2.1)$ & $2.27(1.8,2.9)$ \\
\hline negative $\geqslant 1 \mathrm{~mm}(5: 1+5: 2)$ & $0.6(88)$ & $1.73(1.3,2.2)$ & $2.20(1.5,3.3)$ & $3.8(114)$ & $2.29(1.9,2.8)$ & $3.15(2.4,4.1)$ \\
\hline \multicolumn{7}{|l|}{ PR interval } \\
\hline$\geqslant 0.22 \mathrm{~s}(6: 3)$ & $2.4(364)$ & $0.95(0.8,1.1)$ & $1.11(0.9,1.4)$ & $3.1(86)$ & $1.10(0.9,1.4)$ & $1.14(0.8,1.7)$ \\
\hline$<0.12$ s $(6: 5)$ & $0.6(66)$ & $1.49(1.1,2.1)$ & $0.89(0.4,1.9)$ & $1.0(10)$ & $0.89(0.4,1.9)$ & $0.95(0.3,2.9)$ \\
\hline \multicolumn{7}{|l|}{ Ventricular conduction defect } \\
\hline left bundle branch block $(7: 1)$ & $0.4 \quad(54)$ & $1.35(1.0,1.9)$ & $1.67(1.0,2.9)$ & $1.6(47)$ & $2.86(2.1,3.9)$ & $3.52(2.3,5.3)$ \\
\hline right bundle branch block $(7: 2)$ & 1.1 (163) & $1.07(0.9,1.3)$ & $1.08(0.7,1.6)$ & $1.0(28)$ & $1.41(0.9,2.2)$ & $1.25(0.6,2.4)$ \\
\hline intraventricular block $(7: 4)$ & $0.6(96)$ & $1.00(0.7,1.4)$ & $1.19(0.7,1.9)$ & $1.0(32)$ & $1.88(1.3,2.8)$ & $1.79(1.0,3.2)$ \\
\hline \multicolumn{7}{|l|}{ Arrhythmias } \\
\hline frequent ectopics $(8: 1)$ & $1.4 \quad(204)$ & $1.17(1.0,1.4)$ & $1.32(1.0,1.8)$ & $2.0(59)$ & $1.43(1.1,1.9)$ & $1.34(0.9,2.1)$ \\
\hline atrial fibrillation (8:3) & $0.2(30)$ & $1.95(1.3,2.9)$ & $3.22(1.8,5.7)$ & $1.4(45)$ & $1.86(1.3,2.6)$ & $1.18(0.6,2.2)$ \\
\hline sinus tachycardia $(>100 / \mathrm{min})(8: 7)$ & $2.4(366)$ & $1.30(1.1,1.5)$ & $1.39(1.1,1.8)$ & $2.1(54)$ & $1.83(1.3,2.5)$ & $2.20(1.4,3.4)$ \\
\hline sinus bradycardia $(<50 / \mathrm{min})(8: 8)$ & $1.3(201)$ & $0.78(0.6,1.0)$ & $0.69(0.4,1.1)$ & $1.2(33)$ & $1.08(0.7,1.7)$ & $0.98(0.5,2.0)$ \\
\hline Low QRS amplitude $(9: 1)$ & $0.4(60)$ & $1.12(0.8,1.6)$ & $0.50(0.2,1.3)$ & $0.5(13)$ & $1.26(0.7,2.3)$ & $1.10(0.4,3.0)$ \\
\hline
\end{tabular}

*All hazard ratios are compared with the absence of the specific ECG abnormality. $†$ Numbers of men and deaths in the analyses will be slightly fewer because of differing numbers of missing values for each specific ECG abnormality. 


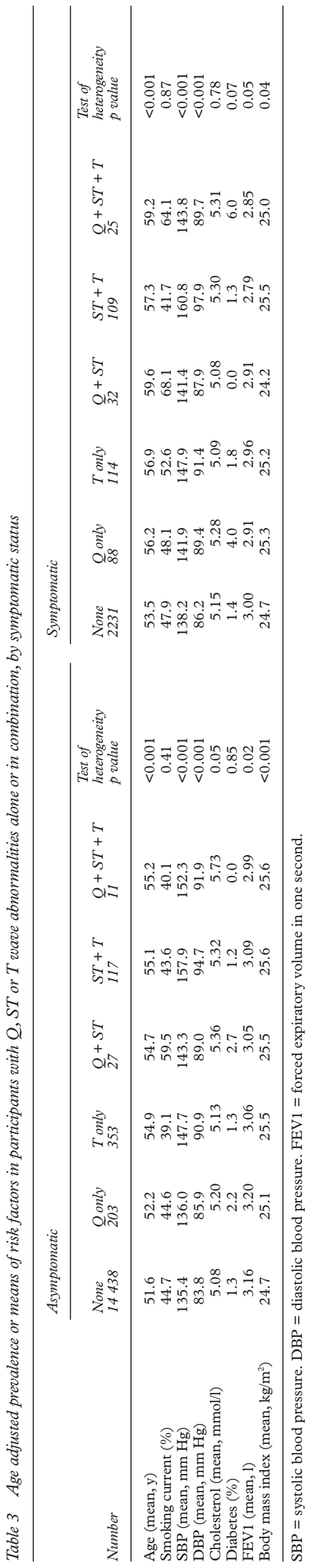

on the left arm by specially trained observers using the London School of Hygiene random zero sphygmomanometer. Plasma cholesterol, fasting and two hour post-load glucose, height, weight and forced expiratory volume in one second (FEV1), were determined in standardised fashion.

MORTALITY

Records from $99.3 \%$ of the participants, were identified and flagged at the National Health Service Central Registry who notified us of all deaths up to the end of January 1995 and provided a copy of the death certificate. After exclusion of a further 94 men with unknown symptomatic status, a total of 17907 men with mortality follow up were available for analysis. These men have been followed up for a minimum of 25 years, during which time there have been 8005 deaths. Death certificates were coded by the Office of Population Censuses and Surveys, according to the eighth Revision of the International Classification of Diseases. Coronary heart disease was defined by ICD- 8 codes 410-414.

\section{STATISTICAL METHODS}

Age adjusted mortality rates, means and proportions were calculated by direct standardisation using the total Whitehall study population as the standard. For continuous variables, tests of heterogeneity in means were assessed by the significance of the ECG groups fitted as a factor in linear regression models with age group as a covariate. For dichotomous variables, the tests of heterogeneity of proportions were assessed using Cochran-MantelHaenszel tests of association with the ECG groups stratified by age group. Adjusted mortality hazard ratios and their confidence intervals were estimated using Cox's proportional hazards regression models. The relations of employment grade both to CHD mortality and the prevalence of ECG abnormalities were linear. Odds ratios for the prevalence of ECG abnormalities in the lowest compares with highest grades were therefore estimated using logistic regression from a linear trend term across grades. This method provides a more precise estimate of the grade effect than just comparing the two extreme grades. The effects of grade on CHD mortality were similarly estimated using a linear trend term for grade in proportional hazards models. All analyses were performed using the statistical package SAS. ${ }^{20}$

\section{Results}

There were monotonic inverse associations between employment grade and age adjusted prevalence of CHD symptoms and CHD mortality ( $p$ for linear trend across grade $<0.001$, table 1). The age adjusted odds ratios for the lowest versus highest grade for CHD symptoms was $1.53(95 \% \mathrm{CI} 1.2,1.9)$. The age adjusted hazard ratio for CHD mortality for the lowest versus highest employment grade was 1.56 (95\% CI 1.2, 2.1).

Table 2 shows the effect of the presence compared with the absence of each specific ECG abnormality on all cause and coronary 


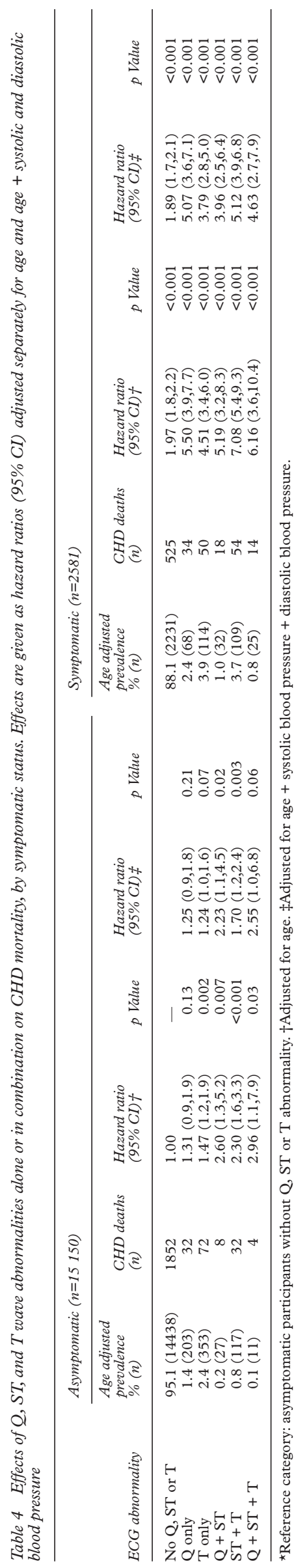

KEY POINTS

- Few population-based studies have compared the inverse association between socioeconomic status (SES) and coronary heart disease (CHD) mortality separately among people with and without prevalent CHD

- In this study of more than 17000 male civil servants, $31 \%$ of CHD deaths occurred in those with prevalent CHD at baseline based on symptoms or Q, ST or $\mathrm{T}$ wave electrocardiographic abnormalities

- The inverse SES-CHD mortality relation was seen in those with and without prevalent CHD

- Further investigation of the relative contribution of SES to the initiation and progression of $\mathrm{CHD}$ requires repeated measures studies of pre-clinical and clinical measures of $\mathrm{CHD}$

mortality by symptomatic status. Most of the ECG abnormalities were associated with an age adjusted increase in risk of mortality in both symptomatic and, to a lesser extent, asymptomatic participants. Most of the abnormalities were more prevalent among symptomatic participants. However, among asymptomatic participants, effects on CHD with hazard ratios $>2$ were found for ST depression $(>0$ $\mathrm{mm}$ and $<1 \mathrm{~mm}$, hazard ratio 2.26 (95\% CI $1.6,3.2)$ ), $\mathrm{T}$ wave inversion ( $\geqslant 1 \mathrm{~mm}$, hazard ratio 2.20 (95\% CI $1.5,3.3)$ ) and atrial fibrillation (hazard ratio 3.22 (95\% CI 1.8, 5.7)). The numbers of participants with right axis deviation $(n=2$, code $2: 2)$, third degree heart block ( $n=0$, code $6: 1)$, second degree heart block ( $n=3$, code 6:2) and Wolf Parkinson White syndrome $(n=4$, code $6: 4)$ were too low to permit mortality analyses.

The validity of the case definitions of prevalent CHD was investigated by examining associations cross sectionally with CHD risk factors (table 3 ) and longitudinally with CHD mortality (table 4).

Table 3 shows the associations of Q (1:1$1: 3)$, ST (4:1-4:3) and T (5:1-5:3) abnormalities alone (in order to distinguish the effect of different Minnesota codes coexisting on the same ECG) or in combination, on CHD risk factors. There were five combinations of abnormality (no participants had $\mathrm{Q}$ and $\mathrm{T}$ abnormalities only and three participants had only ST abnormalities). The presence of ECG abnormalities was most strongly associated with increasing age and higher systolic blood pressure and diastolic blood pressure.

The effects of these five combinations of ECG abnormality on CHD mortality separately adjusted for age and age + systolic + diastolic blood pressure are shown in table 4 . Asymptomatic individuals without any QT, ST or $\mathrm{T}$ abnormalities were used as the comparison group for all the analyses in table 4. Among asymptomatic participants, the hazard of CHD death was progressively greater among those with one, two and three abnormalities of the Q, 
Table 5 Effect of low compared with high employment grade on CHD mortality by ECG abnormality and symptomatic status. Effects are given as hazard ratios (95\% CI) adjusted separately for age and age + systolic + diastolic blood pressure

\begin{tabular}{|c|c|c|c|c|c|c|c|c|}
\hline \multirow[b]{2}{*}{ ECG abnormality } & \multicolumn{4}{|c|}{ Asymptomatic $(n=15$ 150) } & \multicolumn{4}{|c|}{ Symptomatic $(n=2581)$} \\
\hline & Adjusted for age & $p$ Value & $\begin{array}{l}\text { Adjusted for age }+ \\
S B P+D B P\end{array}$ & $p$ Value & Adjusted for age & $p$ Value & $\begin{array}{l}\text { Adjusted for age }+ \\
S B P+D B P\end{array}$ & $p$ Value \\
\hline No Q, ST or T abnormality & $1.81(1.5,2.2)$ & $<0.001$ & $1.72(1.4,2.1)$ & $<0.001$ & $1.52(1.1,2.1)$ & 0.02 & $1.52(1.1,2.1)$ & 0.02 \\
\hline Any Q, ST or T & $1.48(0.8,2.9)$ & 0.25 & $1.46(0.7,2.9)$ & 0.27 & $1.11(0.6,2.0)$ & 0.71 & $1.14(0.6,2.0)$ & 0.65 \\
\hline
\end{tabular}

$\mathrm{ST}$, and $\mathrm{T}$ waves ( $\mathrm{p}$ for trend $<0.001$ ). Among those with symptoms, each of the five combinations was more prevalent than among those without symptoms; and the relative effect on mortality was greater. Sixty nine per cent (1852 of 2695) of the CHD deaths occurred in those without either symptoms or Q, ST or T abnormalities.

So called "minor" $\mathrm{T}$ wave abnormalities (zero, negative or diphasic $\mathrm{T}$ waves, 5:3) were associated with risk of CHD, in the absence of ST or other abnormalities, with hazard ratios of $1.58(95 \%$ CI $1.3,2.0)$ and $2.06(95 \%$ CI 1.6 , 2.7 ) in asymptomatic and symptomatic participants respectively. The 4:4 code was removed because of small numbers and lack of effect on CHD mortality.

Employment grade was associated with the prevalence of any Q, ST and T wave abnormality among symptomatic participants. The odds ratio for the prevalence of any such abnormality in people with symptoms for the lowest versus highest grade was 1.77 (95\% CI 1.1, 2.7)), an effect explained by Q only, $\mathrm{T}$ only and Q + ST abnormality. Employment grade was not associated with the prevalence of Q, ST and T wave abnormality among asymptomatic participants (odds ratio of the prevalence of any Q, ST or $\mathrm{T}$ abnormality for the lowest versus highest grade was 1.12 (95\% CI $0.8,1.5)$ ). There was an inverse association of atrial fibrillation and low QRS amplitude with grade among asymptomatic participants; none of the other ECG abnormalities was associated with grade (data not shown).

Table 5 shows that CHD mortality was inversely associated with employment grade in people with no Q, ST or T abnormality in asymptomatic and symptomatic participants (hazard ratios 1.81 (95\% CI 1.5, 2.2) and 1.52 (95\% CI 1.1, 2.1) respectively). In the presence of any of these ECG abnormalities, the inverse association of employment grade with $\mathrm{CHD}$ was not statistically significant. Although the point estimates among those with any Q, ST or $\mathrm{T}$ abnormality were lower than those without, the $\mathrm{p}$ values for these differences were $>0.3$. Additional adjustment for systolic and diastolic blood pressure had little effect on any of these estimates. For all cause mortality, the findings in relation to employment grade and ECG abnormality were similar to those for CHD mortality.

\section{Discussion}

In a prospective study of over 17000 civil servants followed up for 25 years, there was an inverse association between SES and CHD mortality in participants with and without prevalent CHD at baseline.
The inverse social gradient in CHD mortality could be a result of increased incidence (aetiology), case fatality (prognosis) or both among those of lower SES. Case fatality includes both survival of an acute event, such as myocardial infarction, and prognosis in chronic manifestations of CHD, such as angina. We studied the latter-established CHD in a working population - and found a significant effect of SES on CHD mortality among those with prevalent CHD defined by symptomatic status. When prevalent CHD was defined by $\mathrm{Q}, \mathrm{ST}$ or $\mathrm{T}$ abnormality in the absence of symptoms, the SES effect was similar but the confidence intervals spanned unity. Participants with both symptoms and ECG abnormality were at very high risk (relative to those without symptoms or any ECG abnormality) and in this group there was little evidence of SES effect. This is consistent with a diminution of influence of SES in the face of such competing risks.

Over 25 year follow up there were 843 CHD deaths (nearly one third of all CHD deaths) in participants with CHD at baseline. Despite this large number of events overall, there was a relatively small number of CHD events occurring among participants with prevalent ECG abnormality in the absence of symptoms, raising the possibility of type II error.

The main limitation of this study is that cases of CHD were defined cross sectionally at baseline. It is not known whether people who were asymptomatic and without ECG abnormality at baseline became cases before CHD death. We examined case fatality in an employed population sample of prevalent cases of CHD, in which survival of acute manifestations of CHD may already have been influenced by grade. This problem can only partly be surmounted by studying incident non-fatal myocardial infarction, where the timing and newness of the event are readily defined. By contrast, defining the stage at which a person becomes a pre-clinical case of CHD or a case of angina is less straightforward. There is a growing recognition that pre-clinical abnormalities of vascular structure and function are present in early life, ${ }^{21}$ develop through mid-life and precede the onset of the range of clinical manifestations of CHD. Therefore, to elucidate further the relative contribution of incidence and case fatality to the social gradient in coronary disease, longitudinal repeated measures studies are required that examine the effect of SES on the development over time of interrelations between pathophysiology, symptoms, becoming a case, case severity and the impact of medical care. In the absence of direct measures of coronary artery pathophysiology suitable for 
use in epidemiological studies, carotid intimamedia thickness is proving a valid tool for investigating SES effects on pre-clinical and clinical disease. ${ }^{22-24}$

We defined a prevalent case of CHD as having electrocardiographic abnormality (of Q, ST or $\mathrm{T}$ wave), symptoms (defined by the Rose chest pain questionnaire and self reported doctor diagnosis) or both. The validity of these case definitions was supported by their associations with CHD risk factors and with CHD mortality. As ST and T wave changes might reflect effects of blood pressure as well as ischaemia we adjusted for systolic and diastolic blood pressure; the generally small effects of such adjustments support the electrocardiographic measures as markers of ischaemia. Furthermore, consistent with other studies, ${ }^{10-12}$ flat, negative or diphasic $\mathrm{T}$ waves were associated with CHD mortality even in those without symptoms (such changes should not therefore be called "minor or mild") and in those without symptoms there was a linear association between the number of ECG abnormalities $(0,1,2)$ and subsequent $\mathrm{CHD}$ mortality.

In the context of epidemiological study the ECG remains the only non-invasive means of defining pre-clinical early cardiac abnormality for which long term mortality follow up data are available. This allowed examination of specific causal mechanisms (putative role of ST segment) and potential sources of bias (for example, reporting bias) to be investigated. While the resting ECG is valid in defining $\mathrm{CHD},{ }^{25}$ two observations suggest that qualitative (present/absent) measures of ECG abnormality using the Minnesota code in the six limb lead ECG may not be sufficient to investigate SES-CHD mechanisms. Firstly, there was no evidence that SES was associated with preclinical disease indicated by the presence of $\mathrm{Q}$, $\mathrm{ST}$ or $\mathrm{T}$ abnormalities amongst those without symptoms. Secondly, a specific effect of SES on the ST segment might have been anticipated as the ST segment is influenced by psychosocial stressors, ${ }^{26-31}$ which themselves have been proposed as mediators of the SES-CHD relation. ${ }^{32-34}$ We found no evidence that employment grade was related to resting ECG ST-T wave abnormalities. However, six limb lead ECGs underestimate the true prevalence of ST and other abnormalities found in the chest leads (V1-V6), which are available only on a 12 lead ECG. Quantitative ECG measures from the ECG, for example of parasympathetic:sympathetic balance using heart rate variability, may prove more promising tools for the investigation of the SES-CHD relation. ${ }^{35} 36$

A further reason why prevalent CHD was defined separately in those with and without symptoms was because SES may affect the reporting of symptoms. Barsky has proposed that in "silent ischaemia" it is the patient rather than the ECG who is silent and therefore SES may affect symptom perception, attribution and denial as well as visceral and central pain mechanisms. ${ }^{7}$ The data presented here argue against an important reporting bias by SES, as grade was both inversely associated with reporting symptoms and with CHD mortality separately in those with and without symptoms.

As policy interest in tackling social inequalities in health has been renewed, ${ }^{37}{ }^{38}$ what are the implications of these findings for prevention or treatment? In absolute termsimportant for public health-measures that reduce social differences in coronary risk before people develop ECG changes or symptoms will have the greatest impact. Such measures might include changes at the population or individual level in income distribution, health behaviours and the psychosocial environment. Inferences about the impact of medical care on the SES-CHD relation cannot be made from the data presented here. Among people with symptoms, who are more likely to be under medical care, the point estimates for the effect of SES on CHD mortality were smaller than for those without, although the respective $95 \%$ confidence intervals overlapped. This observation is equally consistent both with an effect of medical care in mitigating the impact of SES or in SES having a lesser effect in cases compared with noncases, regardless of medical care. This issue has rarely been studied, although it is worth noting that in the stepped care arm of the Hypertension Detection and Follow Up Programme, education differences in mortality were abolished. ${ }^{39}$

In summary, SES measured by employment grade was inversely associated with CHD mortality in civil servants with and without prevalent CHD at baseline. The effects among prevalent cases depended on the definition of CHD: they were significant for participants who were symptomatic only; consistent but not significant for ECG abnormality only and were lacking in the highest risk group with both symptoms and ECG abnormality. Distinguishing the relative contribution of SES to the initiation and progression of CHD requires repeated measures studies of pre-clinical and clinical measures of CHD.

Funding: MM is supported by an MRC Research Professorship. MS is supported by the British Heart Foundation. Conflicts of interest: none

1 Kaplan GA, Keil JE. Socioeconomic factors and cardiovascular disease: a review of the literature. Circulation 1993;88:1973-98.

2 Drever F, Whitehead M. Health inequalities: Decennial Supplement. Series DS No.15. London: Office for National Statistics, 1997:1-257.

3 Ruberman W, Weinblatt E, Goldberg JD, et al. Psychosocial influences on mortality after myocardial infarction. $N$ Engl (j)

4 Williams RB, Barefoot JC, Califf RM, et al. Prognostic importance of social and economic resources among medically treated patients with angiographically documented coronary artery disease. $7 A M A$ 1992;267:520-4

5 Lynch JW, Kaplan GA, Cohen RD, et al. Do cardiovascular risk factors explain the relation between socioeconomic status, risk of all-cause mortality, cardiovascular mortality, and acute myocardial infarction? Am f Epidemiol 1996;144: $934-42$

6 Murabito JM, Evans JC, Larson MG, et al. Prognosis after the onset of coronary heart disease: an investigation of differences in outcome between the sexes according to initial coronary disease presentation. Circulation 1993;88.2548 55

7 Barsky AJH, B.Coles. Silent myocardial ischaemia. Is the person or the event silent? $\mathcal{F A M A}$ 1990;264:1132-5.

8 Morrison C, Woodward M, Leslie W, et al. Effect of socioeconomic group on incidence of, management of, and socioeconomic group on incidence of, management of, and
survival after myocardial infarction and coronary death: 
analysis of community coronary event register. $B M \mathcal{F} 1997$; 314:541-6.

Payne N, Saul C. Variations in the use of cardiology services in a health authority: comparison of coronary artery revascularisation rates with the prevalence of angina and coronary mortality. BMF 1997;314:257-61.

10 Sigurdsson E, Thorgeirsson G, Sigvaldason $\mathrm{H}$, et al. Prognostic role of cardiovascular risk factors in men with cardiomegaly (the Reykyavik study). Am f Cardiol 1996;78: 1355-61.

11 Anonymous. Baseline risk factors and their association with outcome in the West of Scotland Coronary Prevention Study. The West of Scotland Coronary Prevention Study Group [see comments]. Am f Cardiol 1997;79:756-62.

12 Daviglus ML, Liao Y, Greenland P, et al. Association of nonspecific minor ST-T abnormalities with cardiovascular mortality: the Chicago Western Electric Study [see comments]. FAMA 1999;281:530-6.

13 Marmot MG, Shipley MJ. Do socioeconomic differences in mortality persist after retirement? 25 year follow up of civil
servants from the first Whitehall study. $B M \mathcal{F} 1996 ; 313$ : servants $1177-80$.

14 Reid DD, Brett GZ, Hamilton PJS, et al. Cardiorespiratory disease and diabetes among middle aged male civil

15 Marmot MG, Rose G, Shipley M, et al. Employment grade and coronary heart disease in British civil servants. F Epidemiol Community Health 1978;32:244-9.

16 Lewes D. Use of multipoint electrode in electrocardiography. Lancet $1965 ;$ ii: $17-18$

17 Prineas RJ, Crown RS, Blackburn H. The Minnesota code manual of electrocardiographic findings: standards and procedures for measurement and classification. Bristol: John Wright, 1982 .

18 Rose G. The coding of survey electrocardiograms by technicians. Br Heart 7 1965;27:595-7.

19 Rose GA, Blackburn H, Gillum RF, et al. Cardiovascular survey methods. Geneva: WHO, 1982:1-178.

20 SAS. SAS/STAT user's guide. Cary, NC. SAS Institute, 1990

21 Leeson CP, Whincup PH, Cook DG, et al. Flow-mediated dilation in 9- to 11-year-old children: the influence of intrauterine and 2233-8.

22 Lynch J, Kaplan GA, Salonen R, et al. Socioeconomic status and carotid atherosclerosis. Circulation 1995;92:1786-92.

23 Lynch J, Krause N, Kaplan GA, et al. Workplace demands, economic reward, and progression of carotid atherosclerosis. Circulation 1997;96:302-7.

24 Diez-Roux AV, Nieto FJ, Tyroler HA, et al. Social inequalities and atherosclerosis. Am F Epidemiol 1995;141:960-72.

25 Pryor DB, Harrell FE, Jr, Lee KL, et al. Estimating the likelihood of significant coronary artery disease. Am f Med $1983 ; 75: 771-80$.
26 Atterhog JH, Malmberg P. Prevalence of primary T-wave changes in young men and their relationship to psychological and anthropometric data. Clin Cardiol 1981;4:91-7.

27 Gabbay FH, Krantz DS, Kop WJ, et al. Triggers of myocardial ischemia during daily life in patients with coronary artery disease: physical and mental activities, anger and smoking. F Am Coll Cardiol 1996;27:585-92.

28 Blumental JA, Jiang W, Waugh RA, et al. Mental stress-induced ischemia in the laboratory and ambulatory ischemia during daily life: association and hemodynamic features. Circulation 1995;92:2102-8.

29 Gottdiener JS, Krantz DS, Howell RH, et al. Induction of silent myocardial ischemia with mental stress testing: relation to the triggers of ischemia during daily life activities and to ischemic functional severity. $f \mathrm{Am}$ Coll Cardiol 1994;24:1645-51.

30 Legault SE, Langer A, Armstrong PW, et al. Usefulness of ischemic response to mental stress in predicting silent myocardial ischemia during ambulatory monitoring. Am f Cardiol 1995;75:1007-11.

31 Jiang W, Babyak M, Krantz DS, et al. Mental stress-induced myocardial ischemia and cardiac events. $7 A M A$ 1996;275: 1651-6.

32 Marmot M, Bosma H, Hemingway $\mathrm{H}$, et al. Contribution of job control and other risk factors to social variations in coronary heart disease. Lancet 1997;350:235-40.

33 Hemingway $\mathrm{H}$, Marmot $M$. Psychosocial factors in the aetiology and prognosis of coronary heart disease: systematic ology and prognosis of coronary heart disease: systematic 7 .

34 Wamala SP, Mittleman MA, Schenck-Gustafsson K, et al. Potential explanations for the educational gradient in coronary heart disease: a population-based case-control study of Swedish women [published erratum appears in Am $\mathcal{F}$ Public Health 1999 May; 89:785]. Am $\mathcal{F}$ Public Health 1999;89:315-21

35 Liao D, Cai J, Rosamond WD, et al. Cardiac autonomic function and incident coronary heart disease: a populationbased case-cohort study. The ARIC Study. Atherosclerosis Risk in Communities Study. Am f Epidemiol 1997;145: 696-706.

36 Hemingway H. Social and psychosocial influences on sudden cardiac death, ventricular arrhythmia and cardiac autonomic function. In: Malik
London: BMJ Books. (In press).

37 Independent Inquiry. Inequalities in health. London: Stationers Office, 1998

38 Department of Health. Saving lives: our healthier nation. London: Stationery Office, 1999.

39 Tyroler HA. Socioeconomic status in the epidemiology and treatment of hypertension. Hypertension 1989;13 (suppl):I$94-7$ 